\title{
Future Projections of Heavy Precipitation in Kanto and Associated Weather Patterns Using Large Ensemble High-Resolution Simulations
}

\author{
Takafumi Miyasaka ${ }^{1,2,3}$, Hiroaki Kawase ${ }^{2}$, Tosiyuki Nakaegawa ${ }^{2}$, Yukiko Imada ${ }^{2}$, and Izuru Takayabu² \\ ${ }^{1} J a p a n$ Meteorological Business Support Center, Tsukuba, Japan \\ ${ }^{2}$ Meteorological Research Institute, Japan Meteorological Agency, Tsukuba, Japan \\ ${ }^{3}$ Research Center for Advanced Science and Technology, The University of Tokyo, Tokyo, Japan
}

\begin{abstract}
Heavy precipitation in Japan is caused by various phenomena, such as tropical cyclones and the Baiu front, and shows regionalscale variation. Here we investigate extremely heavy precipitation events exceeding the 100-year return period in the Kanto area and future projections of such events using large ensemble climate simulations for periods of several thousand years. To understand these extreme events, associated sea level pressure anomalies over Japan and the surrounding region are classified into four clusters. These cluster means are characterized by (1) a strong anomalous cyclone, (2) a weak anomalous cyclone, (3) an anomalous cyclone accompanied by an anomalous anticyclone to the north, and (4) an anomalous anticyclone to the north. The cluster with a strong anomalous cyclone is accompanied by widely distributed heavy precipitation, and its area-averaged precipitation is predicted to be more enhanced under global warming than that of other clusters, partly because of an increase in the strength of strong tropical cyclones approaching Kanto. The cluster dominated by an anomalous anticyclone is characterized by localized heavy precipitation in the plains area. The relative frequency of this cluster will increase, whereas that of other clusters will decrease under global warming.

(Citation: Miyasaka, T., H. Kawase, T. Nakaegawa, Y. Imada, and I. Takayabu, 2020: Future projections of heavy precipitation in Kanto and associated weather patterns using large ensemble high-resolution simulations. SOLA, 16, 125-131, doi:10.2151/ sola.2020-022.)
\end{abstract}

\section{Introduction}

As global warming caused by increasing greenhouse gas concentrations has continued, Japan in recent years has experienced heavy precipitation events and associated infrastructure damage. For example, Typhoon Hagibis in October 2019 caused unprecedented flooding in eastern Japan including the area of Kanto. The Heavy Rain Event of July 2018 was generated by a continuous supply of moisture into the Baiu front and caused severe flooding and landslides over an extensive area, including western Japan (Shimpo et al. 2019; Sekizawa et al. 2019). Northern Kyushu was severely damaged by the localized heavy precipitation in July 2017 (Takemi 2018). As global warming is expected to lead to increased moisture levels in the atmosphere and enhanced precipitation, future projections of extremely heavy precipitation are important for planning with respect to flood mitigation and prevention to protect human lives, infrastructure, and socioeconomic activities. Because of limited observational records, extremely heavy precipitation has often been investigated using extreme value statistics. Large ensemble simulations can enable investigation of extreme events in a robust manner even for extreme events (Mizuta et al. 2017; Kawase et al. 2019). Heavy precipitation

Corresponding author: Takafumi Miyasaka, Japan Meteorological Business Support Center, 1-1 Nagamine, Tsukuba, Ibaraki 305-0052, Japan. E-mail: miyasaka@mri-jma.go.jp. in Japan is known to be caused by various phenomena, such as typhoons and the Baiu front.

As mechanisms of heavy precipitation and the influence of global warming on these mechanisms show variation at the regional scale (Kawase et al. 2019), future projections of heavy precipitation should be investigated for different area for the purposes of flood mitigation/prevention planning under anticipated global warming. The Ministry of Land, Infrastructure, Transport and Tourism (2019; hereafter MLIT19) concluded that the 100year return value of extremely heavy precipitation in Japan will be enhanced by $20 \%-40 \%$ under a $4-\mathrm{K}$ warmer climate based on extreme value statistics for annual maximum precipitation through depth-area-duration analysis, which measures precipitation intensity for a particular duration and area. The analysis of MLIT19 was based on an ensemble dataset with $5-\mathrm{km}$ grid spacing and dynamically downscaled from a large ensemble simulation (Kawase et al. 2018; Sasai et al. 2019), namely, the Database for Policy Decision Making for Future Climate Change (d4PDF; Mizuta et al. 2017; Fujita et al. 2019). Although that downscaling was conducted using a very high resolution, simulations were conducted for only limited ensemble members. Therefore, the 100-year return value was estimated on the basis of extreme value statistics for the 360-year simulation in most areas, under a mixture of precipitation caused by different mechanisms.

In the present study, heavy precipitation in Kanto is investigated based on several-thousand-year simulations of the large ensemble dataset d4PDF. Dataset d4PDF comprises a global version using a general circulation model (GCM; hereafter d4PDF-GCM) and a regional version using a regional climate model (RCM; d4PDF-RCM) with horizontal resolutions of $60 \mathrm{~km}$ and $20 \mathrm{~km}$, respectively. Dataset d4PDF-RCM can reproduce more realistic precipitation than can d4PDF-GCM because of finer orography (Fig. 1d). Kawase et al. (2019) identified differing characteristics of heavy precipitation to the east of mountain ranges compared with the west on Kyushu. Dataset d4PDF-RCM has been used to investigate the relationships between summertime heavy precipitation in Japan and atmospheric circulation (e.g., Ohba and Sugimoto 2018; Osakada and Nakakita 2018) and to determine future changes in heavy precipitation induced by typhoons approaching Japan (Hatsuzuka et al. 2020).

To conduct a comprehensive investigation of heavy precipitation, the present study considers all phenomena, including typhoon and the Baiu front. We present future projections of extremely heavy precipitation in Kanto with a focus on weather patterns. A classification of weather patterns is proposed to describe those weather conditions that favor extremely heavy precipitation and associated area-scale precipitation distribution, which should be useful for flood mitigation/prevention planning.

\section{Data and methods}

We used a large ensemble climate simulation dataset d4PDFRCM, which is dynamically downscaled from d4PDF-GCM (Mizuta et al. 2017; Fujita et al. 2019). Dataset d4PDF-GCM was constructed using the Meteorological Research Institute Atmo- 
(a) Precipitation histogram

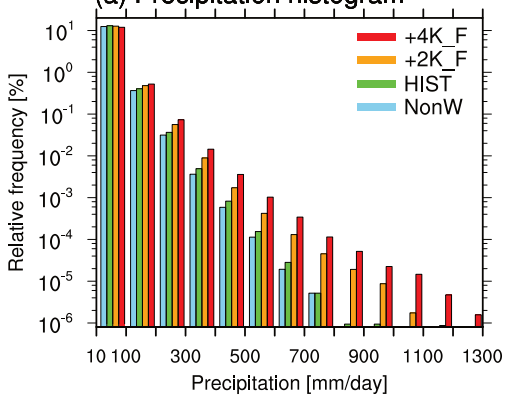

(d) Orography

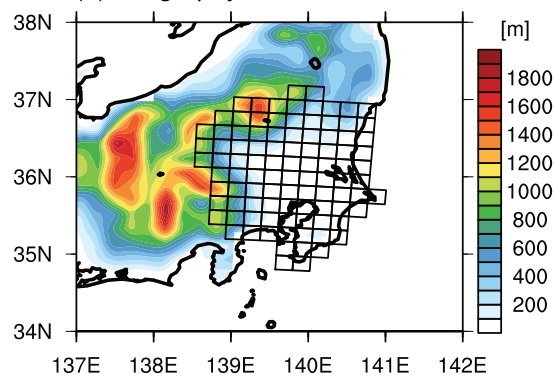

(b) Precipitation percentile

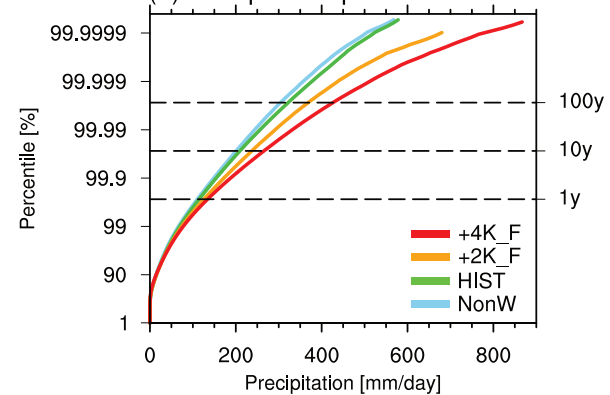

(e) $100-y r$ prec. (+4K_F - HIST)

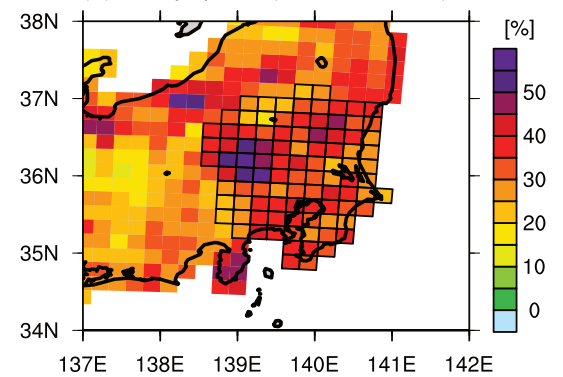

(c) Change of prec. percentile

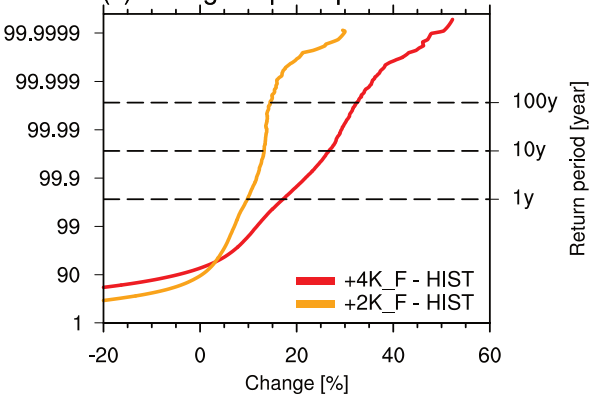

(f) Freq. of 100 -yr prec.

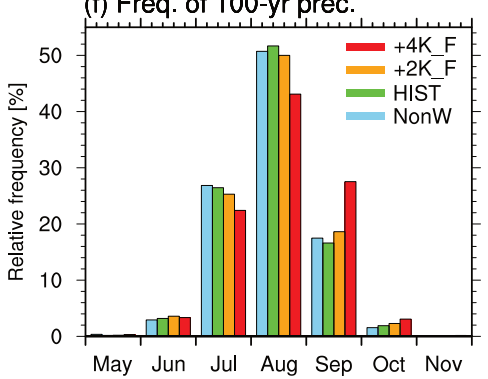

Fig. 1. (a) Relative frequency of daily precipitation in the Kanto area (from grid cells in Fig. 1d-e) based on d4PDF-RCM. (b) Area average precipitation percentiles for grid cells in the Kanto area. (c) Area average future change in precipitation percentile relative to HIST. In (b-c), dashed black lines indicate return periods of 1, 10, and 100 years. (d) Orography of d4PDF-RCM (color) and Kanto grid cells. (e) Percentage change in 100-year extreme precipitation from HIST to +4K_F. (f) Monthly frequency of 100-year extreme precipitation events.

spheric GCM version 3.2 (MRI-AGCM3.2) and has a horizontal resolution of $60 \mathrm{~km}$ (Mizuta et al. 2012). Dataset d4PDF-RCM was constructed for Japan and the surrounding region using the MRI Non-Hydrostatic RCM (NHRCM) and has a 20-km horizontal resolution (Sasaki et al. 2008). Four sets of simulations were conducted: (1) a historical simulation (hereafter HIST) with observed sea surface temperature (SST) dataset COBE-SST2 (Hirahara et al. 2014), (2) a non-warming simulation (hereafter NonW) with detrended COBE-SST2 (Shiogama et al. 2016), and ( 3 and 4) warming simulations for climates that are $4-\mathrm{K}$ and $2-\mathrm{K}$ warmer (hereafter $+4 \mathrm{~K} \_\mathrm{F}$ and $+2 \mathrm{~K} \_\mathrm{F}$ ) than the pre-industrial climate with the NonW SST superimposed on SST warming in six models of the Coupled Model Intercomparison Project phase 5 (CMIP5). The anthropogenic forcings were fixed at a value of 1850 in Non-W, while the forcings in $+2 \mathrm{~K} \mathrm{~F}$ and $+4 \mathrm{~K} \mathrm{~F}$ were based on CMIP5. HIST and NonW are 6000-year simulations for 1951-2010 (100 members of a 60-year simulation), and $+4 \mathrm{~K} \mathrm{~F}$ and +2 K_F are 5400-year and 3240-year simulations, respectively (15 and $\overline{9}$ members of a 60 -year simulation for 6 SST warming distributions, respectively). We analyzed daily data for all calendar months. The climatology is defined as an ensemble mean of a 60year mean for each calendar day, then weakly smoothed using a 15 -day running mean. In warming simulations, daily climatology was evaluated for each of the six SST distributions.

Extremely heavy precipitation events were defined as those days with the 60 heaviest daily precipitations in each model grid for 6000-year simulations of HIST and NonW, which corresponds approximately to precipitation exceeding the 100-year return value (hereafter, 100-year extreme precipitation events). For the $+4 \mathrm{~K} \_$F $\left(+2 \mathrm{~K} \_\right.$F $), 100$-year extreme precipitation events were defined as days with the heaviest 9 (5) daily precipitations for each SST warming distribution, comprising 54 (30) days in total. In composite and cluster analyses, the days for which a 100-year extreme precipitation event was detected in any of the 97 grid cells covering the Kanto area (Fig. 1d) were analyzed (1788 days and 1856 days in HIST and $+4 \mathrm{~K}$ F, respectively). Our analyses thus included extremely heavy precipitation at all spatial scales from Kanto scale to sub-regional scale. The Kanto area was defined on the basis of orography as in MLIT19.

To classify weather patterns associated with 100-year extreme precipitation events, sea level pressure (SLP) anomalies in the whole domain of d4PDF-RCM (Fig. 2a) were decomposed into four clusters. K-means clustering was performed for HIST, then SLP anomalies of $+4 \mathrm{~K} F$ were decomposed into clusters of HIST by using the smallest Euclidian distance from the cluster mean of HIST. This allowed future changes in the classified weather patterns to be examined with respect to changes in the relative frequency and modification of atmospheric circulation.

To investigate the influences of tropical cyclones (TCs) including typhoons, 6-hourly TC track data of d4PDF-GCM (Murakami et al. 2012; Yoshida et al. 2017) were used. A domain within $500 \mathrm{~km}$ of the TC center was considered to be under the direct influence of the TC.

\section{Results}

Under warmer climates, the frequency of heavy precipitation tends to increase in Kanto, whereas the frequency of weak precipitation tends to decrease (Fig. 1a). In +4K_F and +2K_F, extremely heavy precipitation (exceeding the heaviest precipitation in HIST) occurs. Precipitation percentiles indicate that the heavier extreme precipitation is more enhanced under global warming, with $27 \%$ and $32 \%$ (13\% and $15 \%)$ enhancement of 10 -year and 100 -year return values of $+4 \mathrm{~K} \mathrm{~F}(+2 \mathrm{~K} \mathrm{~F})$ compared with HIST, respectively (Figs. $1 \mathrm{~b}$ and $1 \mathrm{c}$ ). Enhancement from HIST to $+2 \mathrm{~K} \_\mathrm{F}$ and $+4 \mathrm{~K} \_\mathrm{F}$ is stronger than that from NonW to HIST, suggesting that damage by flooding and landslides due to heavy precipitation could increase in severity as a result of global warming.

Future changes in 100-year extreme precipitation show regional variation (Fig. 1e). The increase in extreme precipitation tends to be larger in Kanto than that in adjacent areas. The 100year extreme precipitation strengthens by an average of $35 \%$ for the Kanto area, with a maximum strengthening of 58\% (Fig. 1e). The 100-year extreme precipitation occurs from May to November and most frequently in August (Fig. 1f). Under global warming, the frequency of these events from July to August is forecast to decrease, whereas that from September to October will increase, especially in September in $+4 \mathrm{~K}_{-}$F (Fig. 1f). This suggests that future projections of extreme precipitation should be investigated 
(a) HIST SLP anomaly

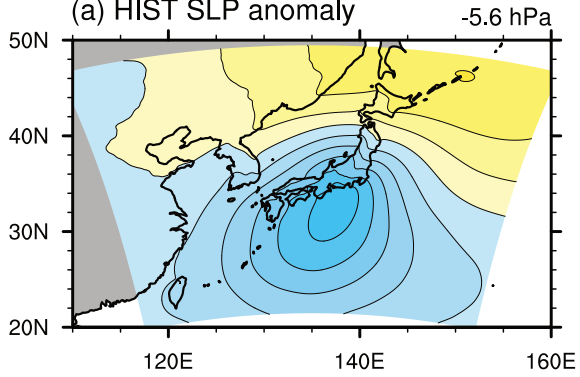

(c) HIST Prec. water $55,42, \& 13 \mathrm{~mm}$

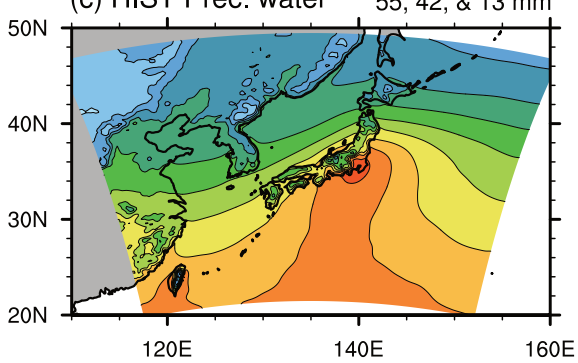

(e) HIST Precipitation

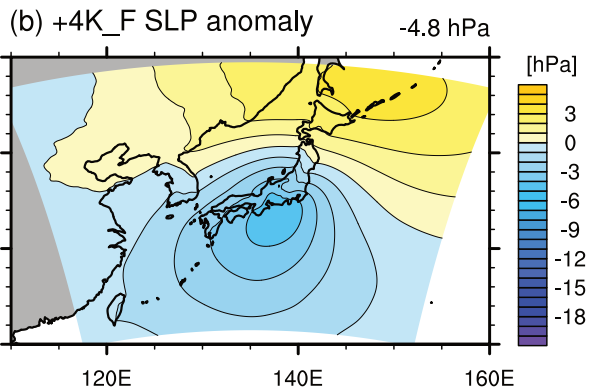

(d) +4 K_F Prec. water $69,54, \& 15 \mathrm{~mm}$

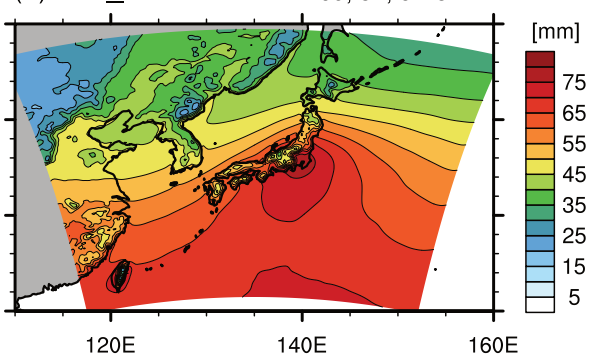

(f) +4 K_F Prec. $\quad 97 \mathrm{~mm} /$ day $(+14 \%)$

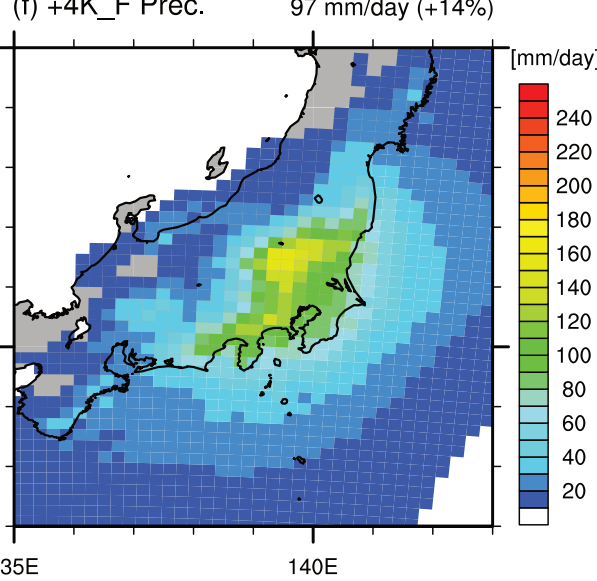

Fig. 2. Composites of $(a-b)$ SLP anomalies, (c-d) precipitable water, and (e-f) precipitation of 100 -year extreme events in (a, c, and e) HIST and (b, d, and f) $+4 \mathrm{~K}$ _F. Values in the upper right of each panel indicate $(\mathrm{a}-\mathrm{b})$ minimum SLP anomaly in composites, (c-d) Kanto-area average of composited precipitable water, counterpart using daily climatology for the event days, and counterpart using anomaly from daily climatology, and (e-f) Kanto-area average of precipitation.

not only for the Baiu season (early summer) but also for autumn.

To determine the typical atmospheric conditions for 100-year extreme precipitation events, composite analysis was conducted. The composite precipitation shows a typical distribution for extreme events (Figs. 2e and 2f) and differs from 100-year return values for the grid cells (Fig. 1b), as the 100-year extreme precipitation does not occur in all grid cells over Kanto at the same time. This analysis was conducted to ascertain the characteristics of extremely heavy precipitation rather than the mechanism of enhancement of the 100-year return value of precipitation.

Composites of SLP anomalies show cyclonic anomalies to the south of Kanto in both HIST and $+4 \mathrm{~K}$ F, which indicates anomalous transport of warm humid air from the Pacific (Figs. 2a and $2 \mathrm{~b})$. Precipitation averaged for Kanto increases by $14 \%$ from 85 to $97 \mathrm{~mm} /$ day (Figs. 2e and 2f) under global warming, although the central SLP anomaly weakens by $14 \%$ from -5.6 to $-4.8 \mathrm{hPa}$. Atmospheric moisture measured by precipitable water increases by $25 \%$ from 55 to $69 \mathrm{~mm}$ (Figs. $2 \mathrm{c}$ and $2 \mathrm{~d}$ ). These changes under 3.9-K warming over Kanto suggest that moisture tends to increase closely to that of the Clausius-Clapeyron (CC) relationship of $\sim 7 \%$ per K (Trenberth et al. 2003), whereas precipitation does not reach that predicted by $\mathrm{CC}$ relationship, probably because of weakened circulation resulting in weakened updrafts by mountainous slope and weakened dynamical updrafts by synoptic disturbances. In that sense, the thermodynamic effect appears to be more important than the dynamic effect for enhancement of heavy precipitation. It is noted that $86 \%$ of the total precipitable water increase $(14 \mathrm{~mm})$ is contributed by climatic increase $(12 \mathrm{~mm})$, suggesting that enhancement of heavy precipitation is closely related to climatic moisture increase under global warming.

As composites for all 100-year extreme precipitation events may include contributions by different mechanisms of heavy precipitation, the events were decomposed into four clusters by applying K-means clustering for SLP anomalies (Fig. 3). Two clusters are characterized by strong and weak cyclonic anomalies, respectively, just to the south of Kanto (hereafter $\mathrm{C} 4$ and $\mathrm{C} 3$, respectively). Another cluster is characterized by meridional SLP anomaly dipole comprised of cyclonic and anticyclonic anomalies to the south and north, respectively $(\mathrm{C} 2)$. The other cluster is characterized by an anticyclonic anomaly to the north and weak local cyclonic circulation over Kanto (C1).

C4 includes more TC events than do other clusters $(34.9 \%$ and $37.8 \%$ in HIST and $+4 \mathrm{~K}$ F, respectively). Cyclonic anomalies in this cluster are enhanced under global warming, unlike in composites of all extreme events (Figs. 2a, 2b, 3d, and 3h), suggesting that the dynamic effect also contributes to enhanced precipitation 
(a) HIST C1 $31.9 \%, 3.3 \%, 0.2 \mathrm{hPa}$

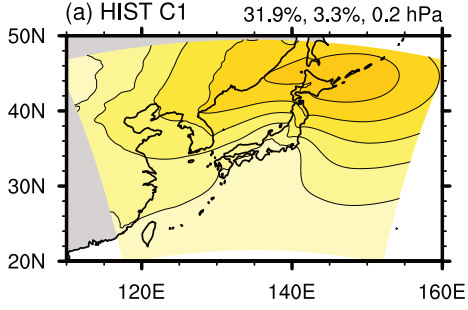

(b) HIST C2
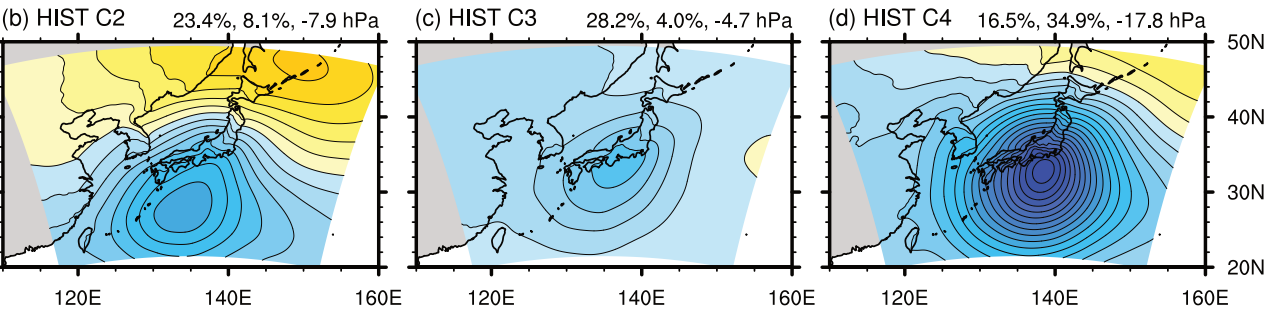

$50 \mathrm{~N}$ (e) $+4 \mathrm{~K} \_\mathrm{F} \mathrm{C1} \quad 40.4 \%, 0.4 \%, 0.3 \mathrm{hPa}$

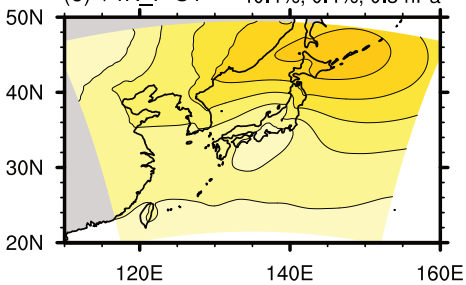

(f) $+4 \mathrm{~K} \_\mathrm{F} \mathrm{C2} \quad 18.8 \%, 6.6 \%,-6.7 \mathrm{hPa}$
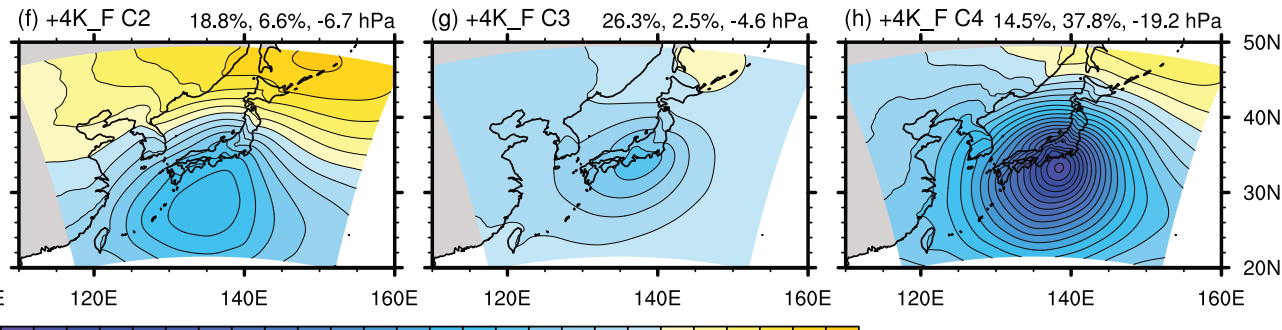

$\begin{array}{lllllllllllll}-20 & -18 & -16 & -14 & -12 & -10 & -8 & -6 & -4 & -2 & 0 & 2 & 4\end{array}$

Fig. 3. Composites of SLP anomalies of the four determined clusters for 100-year extreme precipitation events in (a-d) HIST and (e-h) +4K_F. Values in the upper right of each panel indicate the percentage of each cluster in the total events, the percentage of tropical cyclone events in each cluster, and the minimum SLP anomaly.

(a) HIST C1

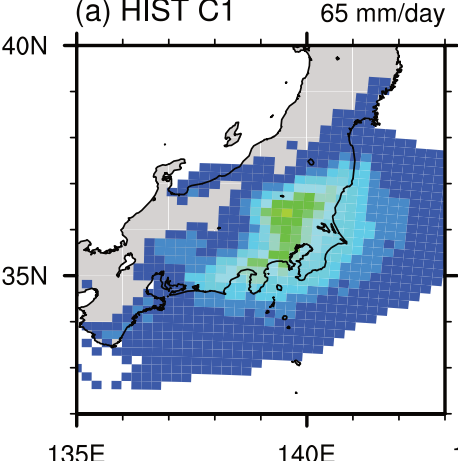

(b) HIST C2

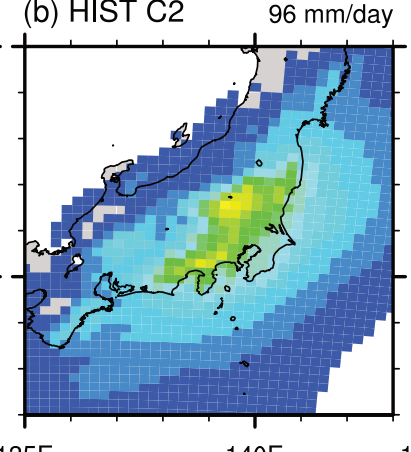

(c) HIST C3

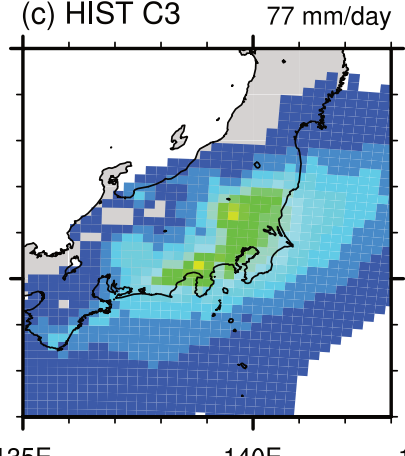

(d) HIST C4 $122 \mathrm{~mm} / \mathrm{day}$

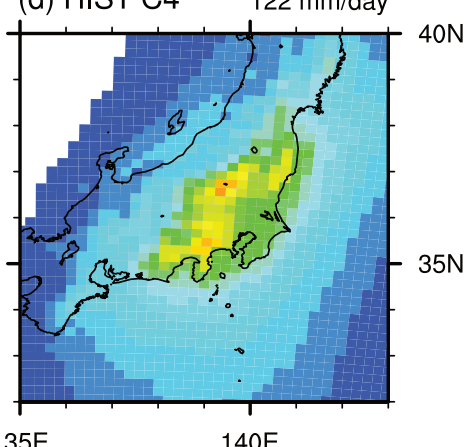

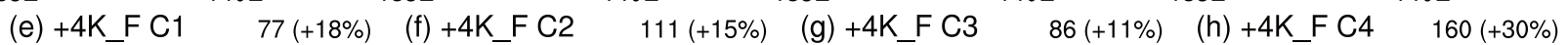

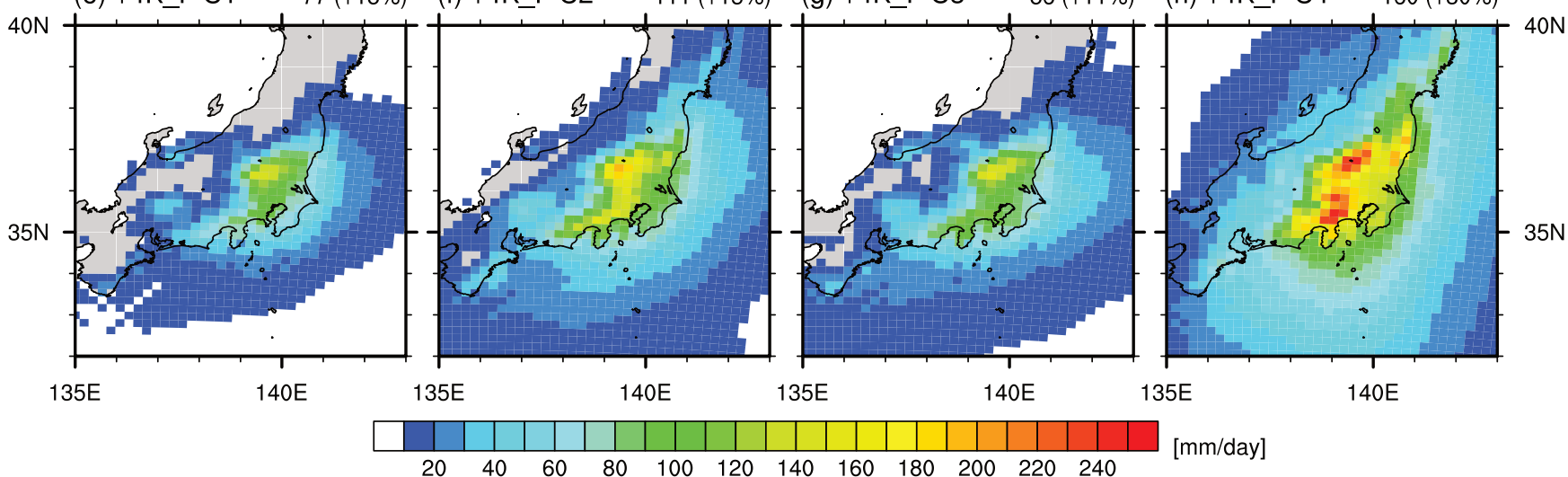

Fig. 4. As for Fig. 3 but for precipitation. Values in the upper right of panels indicate precipitation averaged over the Kanto area, and values in parentheses indicate future change in precipitation.

for this type of extremely heavy precipitation. Precipitation in $\mathrm{C} 4$ is strong in the western part of Kanto along the mountains (Figs. $4 \mathrm{~d}$ and $4 \mathrm{~h}$ ). Area-averaged precipitation in C4 is enhanced by $30 \%$ from 122 to $160 \mathrm{~mm} /$ day, indicating the strongest enhancement of all clusters. The percentage of $\mathrm{C} 4$ events in all extreme events decreases slightly by $2.0 \%$ from $16.5 \%$ to $14.5 \%$.

In $\mathrm{C} 2$ and $\mathrm{C} 3$, cyclonic anomalies weaken under global warming (Figs. $3 b-3 c$ and $3 f-3 g$ ), similar to composites for all extreme events. Precipitation increases by $15 \%$ and $11 \%$, respectively (Fig.
$4 b-4 c$ and $4 f-4 g$ ). Percentages of $C 2$ and $C 3$ events in all extreme events decrease slightly by $4.6 \%$ and $1.9 \%$, respectively.

The percentage of $\mathrm{C} 1$ events in all extreme events is the highest for all clusters and increases under global warming $(31.9 \%$ and $40.4 \%$ in HIST and $+4 K_{-}$F, respectively), in contrast to the decrease seen in the other clusters. C1 is dominated by an anticyclonic anomaly, unlike the other clusters, which have clear cyclonic anomalies. It is therefore inferred that the heavy precipitation in $\mathrm{C} 1$ is associated with unstable atmospheric conditions associated 


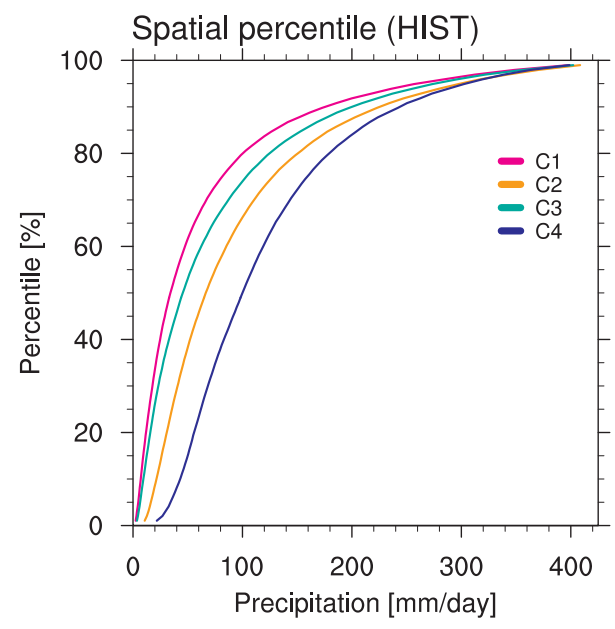

Fig. 5. Averages of the spatial percentile of precipitation for each extreme event in HIST.

with mid-tropospheric cold anomaly (Fig. S1). It is known that summertime Kanto often receives localized showers under unstable atmospheric conditions (Yonetani 1975; Nomura and Takemi 2011). The spatial scale of heavy precipitation, which is measured by the spatial percentile of precipitation, shows that $\mathrm{C} 1$ has the most localized structure of precipitation of the four clusters (Fig. 5). The typical coverage of precipitation exceeding $100 \mathrm{~mm} /$ day accounts for about $20 \%$ of precipitation in $\mathrm{C} 1$, whereas that in $\mathrm{C} 4$ accounts for $50 \%$. Localized heavy precipitation occurs frequently in $\mathrm{C} 1$ (Fig. S2e). Similar localized heavy precipitation without an anomalous cyclone has been observed (Fig. S3). Such convective precipitation in summertime Kanto without synoptic disturbances is projected to be enhanced because of enhanced unstable condition (Takemi 2012; Takemi et al. 2012). Berg et al. (2013) showed that an enhancement of convective precipitation is larger than that of stratiform precipitation in warmer condition, which may contribute to the increased percentage of $\mathrm{C} 1$.

The relative frequency of the 100 -year extreme precipitation shows regional differences among clusters (Fig. 6). The 100year extreme precipitation associated with $\mathrm{C} 4$ tends to occur over mountainous slopes in the western parts of Kanto owing to strong anomalous southeasterlies caused by strong cyclonic anomalies, whereas that associated with $\mathrm{C} 1$ tends to occur over the plains, and that associated with $\mathrm{C} 3$ and $\mathrm{C} 2$ tends to occur in the southeastern and northwestern parts of Kanto. In $+4 \mathrm{~K}$ F , the relative frequency of extreme precipitation shows similar distributions to those in HIST, although C1 tends to occur more frequently in $+4 \mathrm{~K} \_\mathrm{F}$ than in HIST.

It is noted that the percentage of $\mathrm{C} 4$ is projected to decrease under global warming, whereas previous studies showed an increase of strong TCs in the northwestern Pacific (Yoshida et al. 2017) and an increasing frequency of extremely heavy precipitation induced by TCs across Japan (Watanabe et al. 2019). The frequency of TCs with centers within $500 \mathrm{~km}$ of Kanto shows that strong TCs increase and weak TCs decrease with respect to both the central SLP and maximum surface wind speed (Figs. 7c and 7d), consistently with Hatsuzuka et al. (2020). Clear dependence on global warming can be confirmed in decreasing and increasing frequencies of moderate TCs $(960-1000 \mathrm{hPa}$ or $20-40 \mathrm{~m} / \mathrm{s})$ and strong TCs $(<940 \mathrm{hPa}$ or $>50 \mathrm{~m} / \mathrm{s})$, respectively. Precipitation intensity near TCs strengthens for 100 -year extreme precipitation events (Fig. 7a) and for all precipitation near TCs (Fig. 7b). It is suggested that increasing and decreasing percentages of $\mathrm{C} 1$ and $\mathrm{C} 4$, respectively, are associated with the future projection, in which increasing frequency of $\mathrm{C} 1$ overcomes that of strong TCs.

\section{Summary}

The several-thousand-year simulations of the large ensemble simulation dataset d4PDF have allowed us to investigate future projections of extremely heavy precipitation for Kanto, eastern Japan, without any assumptions such as those required by extreme (a) HIST C1

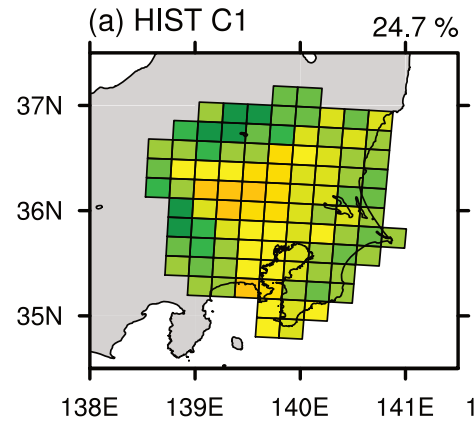

(b) HIST C2

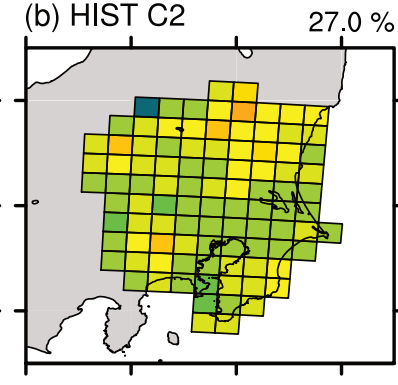

(c) HIST C3

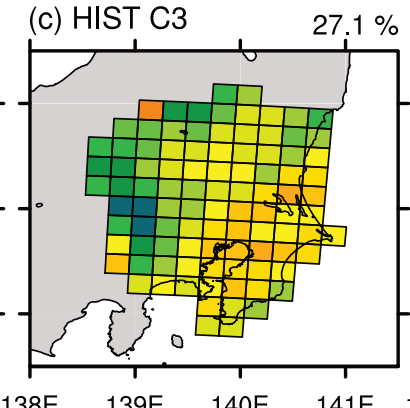

(d) HIST C4

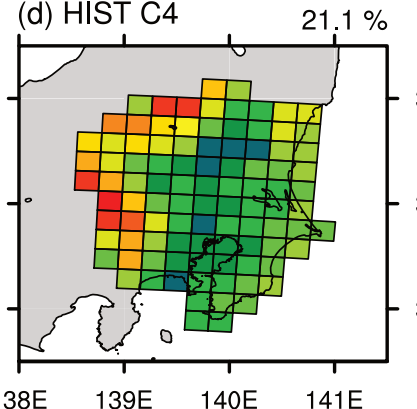

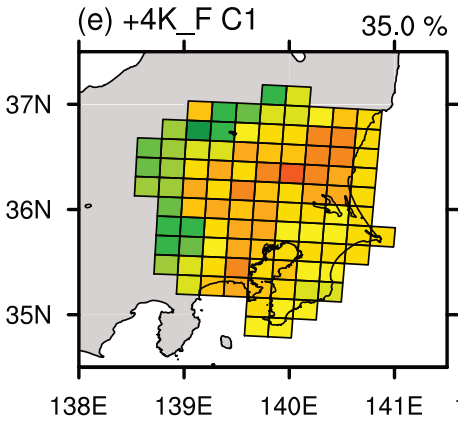

(f) $+4 \mathrm{~K} \_\mathrm{F} \mathrm{C2}$

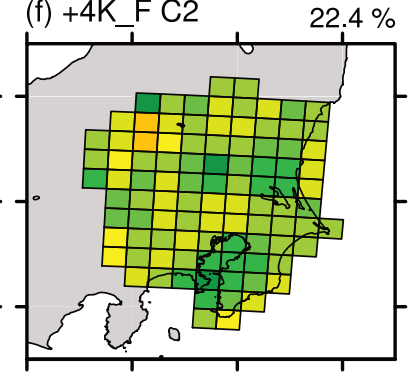

(g) +4 K_F C3

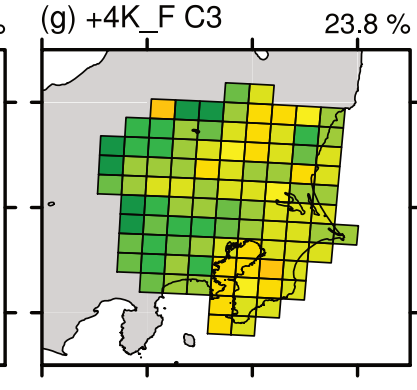

(h) $+4 \mathrm{~K} \_\mathrm{F} \mathrm{C} 4$
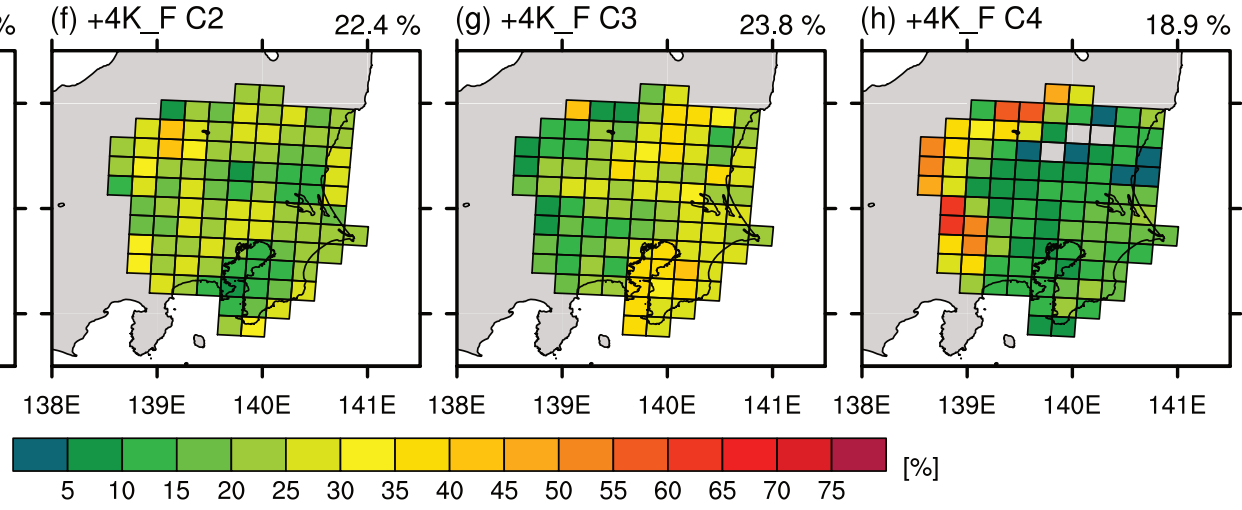

Fig. 6. As for Fig. 3 but for the frequency of 100-year extreme precipitation events in each cluster. The area average is given in the upper right of each panel. Grid cells with no event in a cluster are not colored. 
(a) Prec. change (TCs in 100-yr events)

(b) Prec. change (all TCs)
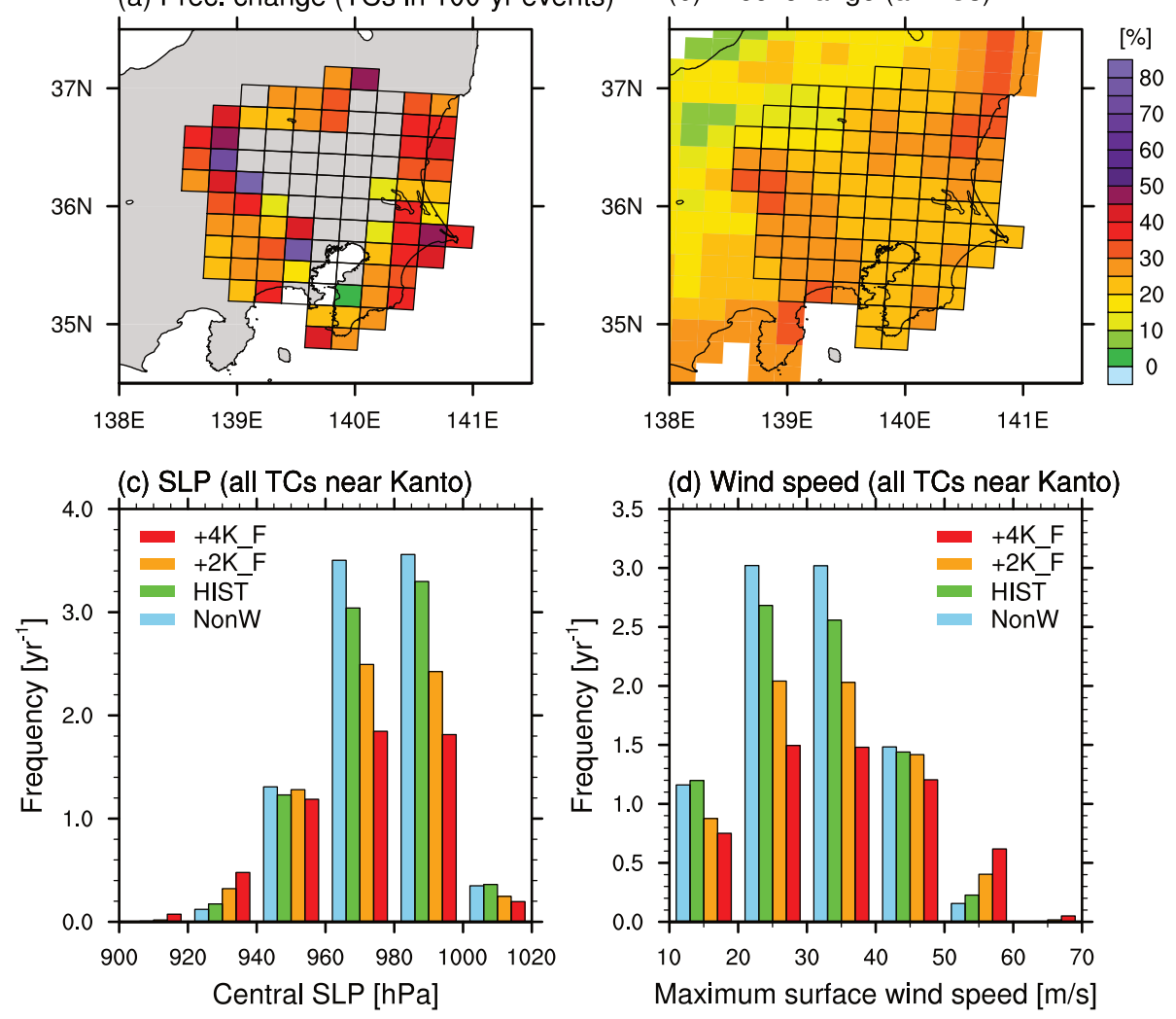

Fig. 7. Future change in daily precipitation under the direct influence of TCs for (a) 100-year extreme precipitation events and (b) all days from March to October. In (a), future change is not evaluated where no TC event is detected in 100-year extreme precipitation events in $+4 \mathrm{~K} \_$F. (c-d) Frequency of 6-hourly (c) central SLP and (d) maximum surface wind speed of TCs whose centers are located within $500 \mathrm{~km}$ of the Kanto area from March to October.

value statistics. We find that the heavier precipitation in Kanto is more enhanced under global warming, with $27 \%$ and $32 \%$ enhancement of 10-year and 100-year return values of 4-K warmer climatic conditions. Weather pattern classification using K-means clustering for SLP anomalies of 100-year extreme precipitation events identifies three clusters with pronounced cyclonic anomalies to the south of Kanto, whereas the most frequent cluster is dominated by anticyclonic SLP anomalies with weak cyclonic circulation over Kanto. The latter cluster occurs more frequently under global warming than in historical simulation. Although all clusters show enhancement of precipitation, cyclonic anomalies weaken except for one cluster with a strong cyclonic anomaly, suggesting that the thermodynamic effect is important for the enhancement of precipitation. The classification reveals that extremely heavy precipitation shows different spatial characteristics among clusters and tends to occur in different parts of Kanto. Furthermore, the relative frequency of extremely heavy precipitation events without the influence of TCs increases, although strengthened TC does contribute to an enhancement of precipitation. The increased relative frequency of extreme events in autumn is associated not with TCs but predominantly with localized heavy precipitation.

Since observational records are too short to validate our analysis for 100-year extreme events, the present study should be revisited in future works. SLP anomaly clustering seems to well classify weather patterns, suggested by small Euclidian distance from cluster mean for $\sim 90 \%$ events (Fig. S4). Meanwhile, the reproducibility of heavy precipitation and TCs may affect relative percentage of the clusters. For validation of our analysis, more deeply understanding of the mechanisms of heavy precipitation formation and future changes in the relative frequency of the main weather patterns are necessary, as well as revisits based on large ensemble simulation dataset using a cloud-resolving model, which has finer resolution than $\mathrm{d} 4 \mathrm{PDF}$.

\section{Acknowledgements}

This research is supported by the Integrated Research Program for Advancing Climate Models (TOUGOU program) Grant Number JPMXD0717935457 and JPMXD0717935561 from the Ministry of Education, Culture, Sports, Science and Technology (MEXT), Japan and the Environment Research and Technology Development Fund JPMEERF20192004 of the Environmental Restoration and Conservation Agency of Japan. This study used d4PDF produced with the Earth Simulator jointly by science programs (SOUSEI, TOUGOU, SI-CAT, DIAS) of MEXT, Japan.

Edited by: T. Takemi

\section{Supplements}

Supplement 1: Supplemental figures.

\section{References}

Berg, P., C. Moseley, and J. O. Haerter, 2013: Strong increase in convective precipitation in response to higher temperatures. Nature Geosci., 6, 181-185, doi:10.1038/NGEO1731.

Fujita, M., R. Mizuta, M. Ishii, H. Endo, T. Sato, Y. Okada, S. Kawazoe, S. Sugimoto, K. Ishihara, and S. Watanabe, 2019: Precipitation changes in a climate with $2-\mathrm{K}$ surface warming from large ensemble simulations using $60-\mathrm{km}$ global and $20-\mathrm{km}$ regional atmospheric models. Geophys. Res. Lett., 46, 435-442, doi:10.1029/2018GL079885.

Hatsuzuka, D., T. Sato, K. Yoshida, M. Ishii, and R. Mizuta, 2020: Regional projection of tropical-cyclone-induced extreme 
precipitation around Japan based on large ensemble simulations. SOLA, 16, 23-29, doi:10.2151/sola.2020-005.

Hirahara, S., M. Ishii, and Y. Fukuda, 2014: Centennial-scale sea surface temperature analysis and its uncertainty. J. Climate, 27, 57-75, doi:10.1175/JCLI-D-12-00837.1.

Kawase, H., Y. Imada, H. Sasaki, T. Nakaegawa, A. Murata, M. Nosaka, and I. Takayabu, 2019: Contribution of historical global warming to local-scale heavy precipitation in western Japan estimated by large ensemble high-resolution simulations. J. Geophys. Res. Atmos., 124, 6093-6103, doi: 10.1029/2018JD030155.

Kawase, H., T. Sasai, T. Yamazaki, R. Ito, K. Dairaku, S. Sugimoto, H. Sasaki, A. Murata, and M. Nosaka, 2018: Characteristics of synoptic conditions for heavy snowfall in western to northeastern Japan analysed by the $5-\mathrm{km}$ regional climate ensemble experiments. J. Meteor. Soc. Japan, 96, 161-178, doi:10.2151/jmsj.2018-022.

Ministry of Land, Infrastructure, Transport and Tourism, 2019: Flood prevention plan associated with climate change. (Available online at: http://www.mlit.go.jp/river/shinngikai blog/chisui_kentoukai/pdf/02_honbun.pdf, accessed 9 Dec 2019) (in Japanese).

Mizuta, R., A. Murata, M. Ishii, H. Shiogama, K. Hibino, N. Mori, O. Arakawa, Y. Imada, K. Yoshida, T. Aoyagi, H. Kawase, M. Mori, Y. Okada, T. Shimura, T. Nagatomo, M. Ikeda, H. Endo, M. Nosaka, M. Arai, C. Takahashi, K. Tanaka, T. Takemi, Y. Tachikawa, K. Temur, Y. Kamae, M. Watanabe, H. Sasaki, A. Kitoh, I. Takayabu, E. Nakakita, and M. Kimoto, 2017: Over 5,000 years of ensemble future climate simulations by $60-\mathrm{km}$ global and $20-\mathrm{km}$ reginal atmospheric models. Bull. Amer. Meteor. Soc., 98, 1383-1398, doi: 10.1175/BAMS-D-16-0099.1.

Mizuta, R., H. Yoshimura, H. Murakami, M. Matsueda, H. Endo, T. Ose, and A. Kitoh, 2012: Climate simulations using MRIAGCM3.2 with 20-km grid. J. Meter. Soc. Japan, 90A, 233-258, doi:10.2151/jmsj.2012-A12.

Murakami, H., R. Mizuta, and E. Shindo, 2012: Future changes in tropical cyclone activity projected by multi-physics and multi-SST ensemble experiments using the 60-km-mesh MRI-AGCM. Climate Dyn., 39, 2569-2584, doi:10.1007/ s00382-011-1223-x.

Nomura, S., and T. Takemi, 2011; Environmental stability for afternoon rain events in the Kanto Plain in summer. SOLA, 7, 9-12, doi:102151/sola.2011-003.

Ohba, M., and S. Sugimoto, 2019: Differences in climate change impacts between weather patterns: Possible effects on spatial heterogeneous changes in future extreme rainfall. Climate Dyn., 52, 4177-4191, doi:10.1007/s00382-018-4374-1.

Osakada, Y., and E. Nakakita, 2018: Future change of occurrence frequency of Baiu heavy rainfall and its linked atmospheric patterns by multiscale analysis. SOLA, 14, 79-85, doi: 102151/sola.2018-014.

Sasai, T., H. Kawase, Y. Kanno, J. Yamaguchi, S. Sugimoto, T. Yamazaki, H. Sasaki, M. Fujita, and T. Iwasaki, 2019: Future projection of extreme heavy snowfall events with a 5-km large ensemble regional climate simulation. $J$. Geophys. Res. Atmos., 124, 13,975-13,990, doi:10.1029/ 2019JD030781.

Sasaki, H., K. Kurihara, I. Takayabu, and T. Uchiyama, 2008:
Preliminary experiments of reproducing the present climate using the non-hydrostatic regional climate model. SOLA, 4, 25-28, doi:102151/sola.2008-007.

Sekizawa, S., T. Miyasaka, H. Nakamura, A. Shimpo, K. Takemura, and S. Maeda, 2019: Anomalous moisture transport and oceanic evaporation during a torrential rainfall event over western Japan in early July 2018. SOLA, 15A, 25-30, doi:10.2151/sola.15A-005.

Shimpo, A., K. Takemura, S. Wakamatsu, H. Togawa, Y. Mochizuki, M. Takekawa, S. Tanaka, K. Yamashita, S. Maeda, R. Kurota, H. Murai, N. Kitabatake, H. Tsuguti, H. Mukougawa, T. Iwasaki, R. Kawamura, M. Kimoto, I. Takayabu, Y. Takayabu, Y. Tanimoto, T. Hirooka, Y. Masumoto, M. Watanabe, K. Tsuboki, and H. Nakamura, 2019: Primary factors behind the heavy rain event of July 2018 and the subsequent heat wave in Japan. SOLA, 15A, 13-18, doi:10.2151/sola. 15A-003.

Shiogama, H., Y. Imada, M. Mori, R. Mizuta, D. Stone, K. Yoshida, O. Arakawa, M. Ikeda, C. Takahashi, M. Arai, M. Ishii, M. Watanabe, and M. Kimoto, 2016: Attributing historical changes in probabilities of record-breaking daily temperature and precipitation extreme events. SOLA, 12, 225-231, doi:10.2151/sola.2016-045.

Takemi, T., 2012: Projected regional-scale changes in atmospheric stability condition for the development of summertime convective precipitation in the Tokyo metropolitan area under global warming. Hydrol. Res. Lett., 6, 17-22, doi:103173/ HRL.6.17.

Takemi, T., 2018: Importance of terrain representation in simulating a stationary convective system for the July 2017 Northern Kyushu heavy rainfall case. SOLA, 14, 153-158, doi:10.2151/sola.2018-027.

Takemi, T., S. Nomura, Y. Oku, and H. Ishikawa, 2012: A regional-scale evaluation of changes in environmental stability for summertime afternoon projection under global warming from super-high-resolution GCM simulations: A study for the case in the Kanto Plain. J. Meter. Soc. Japan, 90A, 181212, doi:10.2151/jmsj.2012-A10.

Trenberth, K. E., A. Dai, R. M. Rasmussen, and D. B. Parsons, 2003: The changing character of precipitation. Bull. Amer. Meteor. Soc., 84, 1205-1217, doi:10.1175/BAMS-84-91205.

Watanabe, S., A. Murata, H. Sasaki, H. Kawase, and M. Nosaka, 2019: Future projection of tropical cyclone precipitation over Japan with a high-resolution regional climate model. $J$. Meteor. Soc. Japan, 97, 805-820, doi:10.2151/jmsj.2019045.

Yonetani, T., 1975: Characteristics of atmospheric vertical structure on days with thunderstorms in the northern Kanto Plain. J. Meteor. Soc. Japan, 53, 139-148, doi:10.2151/jmsj 1965.53.2_139.

Yoshida, K., M. Sugi, R. Mizuta, H. Murakami, and M. Ishii, 2017: Future changes in Tropical cyclone activity in high-resolution large-ensemble simultaions. Geophys. Res. Lett., 44, 9910-9917, doi:10.1002/2017GL075058.

Manuscript received 2 April 2020, accepted 9 June 2020

SOLA: https://www.jstage.jst.go.jp/browse/sola/ 